\title{
CHEMICAL COMPOSITION AND ANTIMICROBIAL ACTIVITY OF THE ESSENTIAL OIL FROM TWIGS AND LEAVES OF Magnolia macclurei (Dandy) Figlar FROM HA GIANG PROVINCE, VIETNAM
}

\author{
Chu Thi Thu Ha ${ }^{1,2, *}$, Tran Huy Thai ${ }^{1,2}$, Le Ngoc Diep ${ }^{1}$, \\ Dinh Thi Thu Thuy ${ }^{3}$, Nguyen Duc Ky ${ }^{4,5}$, Ha Minh Tam ${ }^{5}$ \\ ${ }^{1}$ Institute of Ecology and Biological Resources, VAST, Vietnam \\ ${ }^{2}$ Graduate University of Science and Technology, VAST, Vietnam \\ ${ }^{3}$ Institute of Natural Product Chemistry, VAST, Vietnam \\ ${ }^{4}$ Binh Son Senior High School, Vinh Phuc, Vietnam \\ ${ }^{5}$ Hanoi Pedagogical University No 2, Vinh Phuc, Vietnam \\ Received 24 May 2019, accepted 6 February 2020
}

\begin{abstract}
The chemical composition of the essential oil obtained by hydrodistillation of the twigs and leaves of Magnolia macclurei collected in Hoang Su Phi, Ha Giang Province, Vietnam was analyzed using GC/MS. A total of 38 compounds were detected in essential oil, accounting for $94.49 \%$ of the oil, in which 37 compounds were identified accounting for $93.33 \%$. cis- $\beta$-Elemene $(14,30 \%)$, bicyclogermacrene $(18,57 \%)$, and 10-epi- $\gamma$-eudesmol $(16,86 \%)$ were the main components of essential oil. The minor components present with rather high amount were: Germacrene D $(2,12 \%)$, guaiol $(8,52 \%)$, hinesol $(2,34 \%)$, valerianol $(6,76 \%)$, and bulnesol $(2,93 \%)$. Antibiotic activity of the essential oil sample was tested against a Gram positive bacteria Staphylococcus aureus, a Gram negative bacteria Escherichia coli, and a yeast Candida albicans using an agar disk diffusion method. All three microorganisms tested are resistant to the oil from twigs and leaves of $M$. macclurei. That is exhibited through the inhibitory zone diameters ranging from 4 to $12 \mathrm{~mm}$.
\end{abstract}

Keywords: Magnolia macclurei, antimicrobial activity, essential oil composition.

Citation: Chu Thi Thu Ha, Tran Huy Thai, Le Ngoc Diep, Dinh Thi Thu Thuy, Nguyen Duc Ky, Ha Minh Tam, 2020. Chemical composition and antimicrobial activity of the essential oil from twigs and leaves of Magnolia macclurei (Dandy) Figlar from Ha Giang Province, Vietnam. Tap chi Sinh hoc, 42(1): 41-49. https://doi.org/10.15625/0866-7160/v42n1.13839.

*Corresponding author email: hachuthi@yahoo.com

C2020 Vietnam Academy of Science and Technology (VAST) 


\title{
THÀNH PHẦN HÓA HỌC VÀ HOẠT TÍNH KHÁNG VI SINH VẬT CỦA TINH DẦU CÀNH LÁ GIỐI BÚP NHỘN (Magnolia macclurei (Dandy) Figlar) THU TỪ HÀ GIÁNG, VIẸTT NAM
}

\author{
Chu Thị Thu Hà̀ ${ }^{1,2, *}$, Trần Huy Thái ${ }^{1,2}$, Lê Ngọc Diệp ${ }^{1}$, \\ Đinh Thị Thu Thủy ${ }^{3}$, Nguyễn Đức Kỳ ${ }^{4,5}$, Hà Minh Tâm ${ }^{5}$ \\ ${ }^{1}$ Viện Sinh thái và Tài nguyên sinh vật, Viện Hàn lâm Khoa học và Công nghệ Việt Nam \\ ${ }^{2}$ Học viện Khoa học và Công nghệ, Viện Hàn lâm Khoa học và Công nghệ Việt Nam \\ ${ }^{3}$ Viện Hóa học các hợp chất thiên nhiên, Viện Hàn lâm Khoa học và Công nghệ Việt Nam \\ ${ }^{3}$ Trường Trung học phổ thông Bình Sơn, Vĩnh Phúc \\ ${ }^{4}$ Trường Đại học Sư phạm Hà Nội 2, Vĩnh Phúc \\ Ngày nhận bài 24-5-2019, ngày chấp nhận 6-2-2020
}

\section{TÓM TẮT}

Bằng phương pháp chưng cất lôi cuốn hơi nước, tinh dầu từ cành lá của Giổi búp nhọn, (Magnolia macclurei) mọc tự nhiên ở Hoàng Su Phì, tỉnh Hà Giang đã được phân tích thành phần hóa học nhờ phương pháp sắc ký khí ghép khối phổ (GC/MS). Kết quả cho thấy, tổng số có 38 hợp chất được phát hiện trong tinh dầu, chiếm $94,49 \%$ hàm lượng của tinh dầu, trong đó có 37 hợp chất đã được xác định, chiếm $93,33 \%$. Ba thành phần chính của tinh dầu được xác định gồm: cis- $\beta$-Elemene (14,30\%), bicyclogermacrene (18,57\%), và 10-epi- -eudesmol (16,86\%). Năm hợp chất có hàm lượng tương đối cao trong tinh dầu gồm: Germacrene $\mathrm{D}(2,12 \%)$, guaiol $(8,52 \%)$, hinesol $(2,34 \%)$, valerianol $(6,76 \%)$, và bulnesol $(2,93 \%)$. Hoạt tính kháng vi sinh vật của tinh dầu cành lá $M$. macclurei đã được đánh giá trên một chủng vi khuẩn Gram (+) là Tụ cầu vàng (Staphylococcus aureus), một chủng vi khuẩn Gram (-) là Escherichia coli và một chủng nấm men Candida (Candida albicans) bằng phương pháp khuếch tán đĩa thạch. Cả 3 chủng vi sinh vật được thử nghiệm có tính chịu đựng cao đối với tinh dầu cành lá $M$. macclurei với đường kính vùng ức chế vi sinh vật từ 4 đến $12 \mathrm{~mm}$.

Từ khóa: Magnolia macclurei, hoạt tính kháng khuẩn, thành phần tinh dầu.

*Địa chỉ liên hệ email: hachuthi@ yahoo.com

\section{MỞ ĐẦU}

Giổi búp nhọn còn có tên gọi là Giổi bắc (Magnolia macclurei (Dandy) Figlar) (syn. Michelia macclurei var. sublanea Dandy, Michelia multitepala R.Z.Zhou \& Jian), là cây thân gỗ thuộc chi Mộc lan (Magnolia), họ Ngọc lan (Magnoliaceae). Các loài thuộc chi Magnolia thường được các nhà khoa học quan tâm thông qua nhiều nghiên cứu trong lĩnh vực hóa thực vật, dược học, và tinh dầu vì có giá trị sử dụng trong hệ thống chăm sóc sức khỏe truyền thống cũng như trong ngành công nghiệp nước hoa (Sarker \& Maruyama, 2002; Lee et al., 2011, Zeng et al., 2011). Cành non, chồi, cuống lá, lá kèm, và chồi bên của $M$. macclurei có lông măng dày đặc màu nâu đỏ bóng ngắn hoặc lông nhung rải rác. Cuống lá dài 1,5-4 cm, hướng trục, có nếp nhăn hẹp, không có sẹo lá kèm. Phiến lá hình trứng ngược hoặc hình elip có túm lông màu xám xen với lông măng ngắn áp ép màu nâu, hướng trục; ban đầu có lông tơ, nhưng về sau nhẵn (Vu Quang Nam, 2011). Giổi búp nhọn (M. macclurei) phân bố ở rừng cây lá rộng thường xanh, độ cao 200-1.600 m so với mực 
nước biển. Ở Việt Nam, loài này đã được ghi nhận có phân bố ở Vĩnh Phúc, Quảng Ninh, Lâm Đồng và Gia Lai. Loài này có ở một số tỉnh của Trung Quốc (Vu Quang Nam, 2011).

M. macclurei đã được nghiên cứu trước đây về đặc điểm sinh học sinh thái ( $\mathrm{Vu}$ Quang Nam, 2011), ghi nhận bổ sung loài cho hệ thực vật Việt Nam (Vũ Quang Nam và nnk., 2011), thành phần các hợp chất bay hơi của vỏ cây và hoạt tính ức chế tế bào ung thư gan HepG2 (Song et al., 2011), thành phần các hợp chất bay hơi của lá (Huang et al., 2009), thành phần các hợp chất bay hơi của lá và hoa (Ma et al., 2011). Tuy nhiên, cho đến nay, $M$. macclurei còn ít được nghiên cứu về thành phần hóa học của tinh dầu cành lá và chưa có công bố nào về hoạt tính kháng vi sinh vật của các hợp chất từ tinh dầu. Trong nghiên cứu này, lần đầu tiên chúng tôi trình bày kết quả phân tích thành phần hóa học và hoạt tính kháng vi sinh vật của tinh dầu cành lá Giổi búp nhọn $M$. macclurei thu từ tỉnh Hà Giang.

\section{VÂT LIỆ VÀ PHƯỚNG PHÁP NGHIÊN CƯU}

Mẫu cành lá của Magnolia macclurei được thu vào tháng 4/2018 tại thôn Nậm Piên, xã Nậm Ty, huyện Hoàng Su Phì, Hà Giang, ở độ cao trên $1.600 \mathrm{~m}$. Tên loài thực vật được TS. Nguyễn Tiến Hiệp, Trung tâm Bảo tồn thực vật Việt Nam định danh. Mẫu tiêu bản khô (HG1814) được lưu tại Phòng Tiêu bản thực vật, Viện Sinh thái và Tài nguyên sinh vật $(\mathrm{HN})$, Viện Hàn lâm Khoa học và Công nghệ Việt Nam (VAST). Sử dụng $0,8 \mathrm{~kg}$ mẫu cành lá tươi cắt nhỏ và chưng cất tinh dầu trong 4 giờ theo phương pháp chưng cất lôi cuốn hơi nước sử dụng thiêt bị chưng cất dạng Clevenger. Sau đó, tinh dầu được tách riêng và làm khô bằng $\mathrm{MgSO}_{4}$ khan, được bảo quản ở (-) $5{ }^{\circ} \mathrm{C}$ trước khi phân tích.

Hoạt tính kháng vi sinh vật của tinh dầu được đánh giá bằng cách sử dụng 3 chủng vi khuẩn: Gram (+) Staphylococcus aureus (ATCC 13709), vi khuẩn Gram (-) Escherichia coli (ATCC 25922) và chủng nấm men Candida albicans (ATCC 10231). $\mathrm{Ba}$ chủng vi sinh vật này được nhập từ Bảo tàng chủng giống vi sinh vật Hoa Kỳ (ATCC: American Type Culture Collection).

\section{Phương pháp sắc ký khí ghép khối phổ (Gas Chromatography - Mass Spectrometry)}

Thành phần hóa học của tinh dầu được phân tích tại Viện Hóa học các hợp chất thiên nhiên, Viện Hàn lâm Khoa học và Công nghệ Việt Nam bằng phương pháp sắc ký khí ghép khối phổ GC/MS sử dụng hệ thống sắc ký Agilent GC7890A, đầu dò khối phổ (Mass Selective Detector) Agilent MSD5975C, cột mao quản silica (fused silica capillary column) HP-5MS $60 \mathrm{~m} \times 0,25 \mathrm{~mm} \times 0,25 \mu \mathrm{m}$. Khí mang là Heli với tốc độ dòng là 1,0 $\mathrm{mL} /$ phút. Nhiệt độ buồng bơm mẫu là $250^{\circ} \mathrm{C}$ và chương trình nhiệt độ của lò như sau: $60^{\circ} \mathrm{C}$ đến $240^{\circ} \mathrm{C}$ ở tốc độ $4{ }^{\circ} \mathrm{C} /$ phút với nhiệt độ đuổi cột sau chương trình phân tích là $270^{\circ} \mathrm{C}$. Tỉ lệ chia dòng là $1: 100$, nhiệt độ của đầu dò là $270^{\circ} \mathrm{C}$ và thể tích bơm mẫu là $1 \mu \mathrm{L}$. Nhiệt độ buồng chuyển tiếp là $270^{\circ} \mathrm{C}$, phá mảnh hoàn toàn với hiệu điện thế đầu dò là $70 \mathrm{eV}$, và dãy phổ 35-450 Da ở 4 lần quét/giây. Các thành phần được xác định dựa trên hệ số lưu giữ của chúng (tính toán theo dãy đồng đẳng $\mathrm{n}$ alkanes) và so sánh phổ khối của chúng với dữ liệu phổ khối chất chuẩn lưu trong thư viện phổ (HPCH1607, NIST08, Wiley 09). Hàm lượng tương đối của các thành phần được tính toán dựa trên diện tích píc thu được từ sắc ký đồ. Phần mềm xử lý dữ liệu được sử dụng là Chemstation và phân mềm xử lý phổ khối là MassFinder 4.0 (Robert, 2001; König et al., 2018).

\section{Phương pháp sàng lọc hoạt tính kháng vi sinh vật}

Hoạt tính kháng vi sinh vật của tinh dầu được xác định bằng phương pháp khuếch tán đĩa thạch (Jorgensen \& Ferraro, 2009; Balouiri et al., 2016). Môi trường nuôi cấy vi sinh vật gồm Mueller-Hinton Agar (MHA) dùng cho vi khuẩn và Sabouraud Agar (SA) dùng cho nấm. Vi sinh vật được lưu giữ ở (-) $80^{\circ} \mathrm{C}$ và được hoạt hóa trước khi tiến hành thí nghiệm bằng cách nuôi cấy để đạt được mật độ $1,0 \times 10^{6} \mathrm{CFU} / \mathrm{ml}$ trong môi trường. Lấy $100 \mu \mathrm{l}$ dung dịch nuôi cấy và trải đều trên bề mặt thạch. Dùng kỹ thuật vô trùng tạo 2 lỗ (đường kính mỗi lô̂ $6 \mathrm{~mm}$ ) trên mỗi đĩa thạch và hút $50 \mu \mathrm{l}$ tinh dầu cho vào mỗi lỗ. 
Các đĩa petri này được giữ ở nhiệt độ phòng trong 2-4 giờ, sau đó được ủ ở $37^{\circ} \mathrm{C}$ trong 18-24 giờ. Quan sát và ghi nhận sự tăng trưởng hoặc không tăng trưởng của vi sinh vật xung quanh mỗi lỗ có tác nhân kháng sinh trong mỗi đĩa nuôi cấy. Dùng thước có chia vạch milimet để đo giá trị đường kính của các vùng ức chế vi sinh vật. Vùng ức chế vi sinh vật là nơi không thấy sự tăng trưởng khi quan sát bằng mắt thường. Vùng ức chể bằng hoặc lớn hơn $14 \mathrm{~mm}$ (bao gồm cả đường kính của lỗ) được đánh giá là có hoạt tính kháng vi sinh vật cao (Mothana \& Lindequist, 2005; Philip et al., 2009).

\section{KẾT QUẢ VÀ THẢO LUẬN}

Thành phần hóa học của tinh dầu cành lá Magnolia macclurei

Tinh dầu được chiết tách từ cành lá $M$. macclurei bằng phương pháp chưng cất lôi cuốn hơi nước, có màu vàng nhạt và khối lượng riêng nhỏ hơn nước. Thành phần hóa học của tinh dầu từ cành lá được trình bày trong hình 1, bảng 1 .

Hàm lượng tinh dầu cành lá thu được là 0,254\% (v/w) tính trên trọng lượng khô của mẫu. Tổng số 38 hợp chất đã được phát hiện trong thành phần của tinh dầu chiếm $94,49 \%$ hàm lượng tinh dầu, trong đó có 37 hợp chất đã được xác định chiếm $93,33 \%$. Ba hợp chất gồm: cis- $\beta$-Elemene, bicyclogermacrene, và

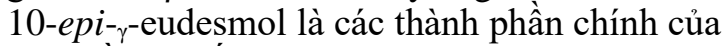
tinh dầu, chiếm tương ứng $14,30 \%, 18,57 \%$, và $16,86 \%$ hàm lượng tinh dầu. Các hợp chất có hàm lượng tương đối lớn tiếp theo chiếm tỉ lệ cao trong thành phần của tinh dầu nghiên cứu gồm: Germacrene $\mathrm{D}(2,12 \%)$, guaiol $(8,52 \%)$, hinesol $(2,34 \%)$, valerianol $(6,76 \%)$, bulnesol $(2,93 \%)$. Hàm lượng của các hợp chất khác còn lại trong tinh dầu dao động trong khoảng $0,11-1,81 \%$ hàm lượng tinh dầu (bảng 1).

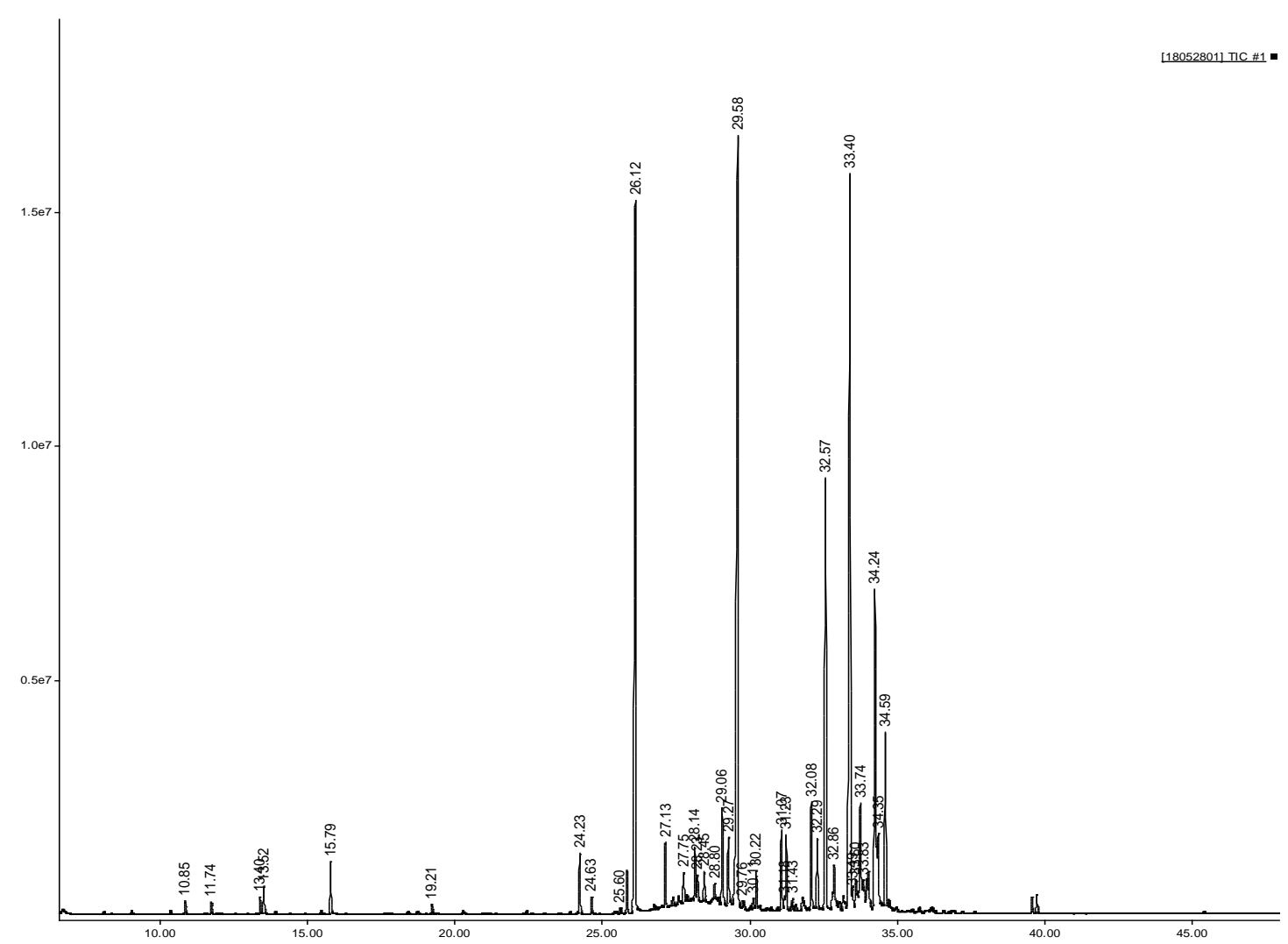

Hình 1. Gas chromatogram of essential oil from twigs and leaves of $M$. macclurei analyzed using GC/MS 
Bảng 1. Composition of essential oil from twigs and leaves of M. macclurei

\begin{tabular}{|c|c|c|c|}
\hline STT & RI & Thành phần & Percent $\%$ \\
\hline 1 & 956 & Camphene & 0,19 \\
\hline 2 & 985 & $\beta$-Pinene & 0,17 \\
\hline 3 & 1035 & Limonene & 0,26 \\
\hline 4 & 1038 & Cineole 1,8 & 0,43 \\
\hline 5 & 1104 & Linalool & 0,80 \\
\hline 6 & 1201 & $\alpha$-Terpineol & 0,14 \\
\hline 7 & 1349 & $\delta$-Elemene & 0,96 \\
\hline 8 & 1361 & $\alpha$-Cubebene & 0,25 \\
\hline 9 & 1390 & $\alpha$-Copaene & 0,11 \\
\hline 10 & 1406 & cis- $\beta$-Elemene & 14,30 \\
\hline 11 & 1438 & $(E)$ - $\beta$-Caryophyllene & 1,20 \\
\hline 12 & 1458 & Aromadendrene & 0,81 \\
\hline 13 & 1470 & unknown $(204,204$, RI 1470) & 1,16 \\
\hline 14 & 1473 & $\alpha$-Humulene & 0,80 \\
\hline 15 & 1480 & 9-epi-(E)-Caryophyllene & 1,22 \\
\hline 16 & 1491 & $\beta$-Chamigrene & 0,60 \\
\hline 17 & 1499 & Germacrene D & 2,12 \\
\hline 18 & 1506 & $\beta$-Selinene & 1,57 \\
\hline 19 & 1517 & Bicyclogermacrene & 18,57 \\
\hline 20 & 1522 & $\delta$-Amorphene & 0,22 \\
\hline 21 & 1534 & ${ }_{\gamma}$-Cadinene & 0,18 \\
\hline 22 & 1538 & $\delta$-Cadinene & 0,56 \\
\hline 23 & 1566 & Elemol & 1,31 \\
\hline 24 & 1570 & $\alpha$-Agarofuran & 0,22 \\
\hline 25 & 1572 & $(E)$-Nerolidol & 1,22 \\
\hline 26 & 1578 & Germacrene B & 0,25 \\
\hline 27 & 1600 & Spathulenol & 1,81 \\
\hline 28 & 1607 & Viridiflorol & 1,30 \\
\hline 29 & 1617 & Guaiol (=Champacol) & 8,52 \\
\hline 30 & 1628 & 5-epi-7-epi- $\alpha$-Eudesmol & 1,08 \\
\hline 31 & 1647 & 10-epi- ${ }_{\gamma}$-Eudesmol & 16,86 \\
\hline 32 & 1650 & 1-epi-Cubenol & 0,46 \\
\hline 33 & 1653 & ${ }_{\gamma}$-Eudesmol & 0,67 \\
\hline 34 & 1659 & Hinesol & 2,34 \\
\hline 35 & 1662 & epi- $\alpha$-Cadinol (=tau-Cadinol) & 0,81 \\
\hline 36 & 1676 & Valerianol & 6,76 \\
\hline 37 & 1680 & neo-Intermedeol & 1,33 \\
\hline \multirow[t]{7}{*}{38} & 1689 & Bulnesol & 2,93 \\
\hline & & Các monoterpene hydrocarbon & 0,62 \\
\hline & & Các monoterpene hydrocarbon chứa oxy & 1,37 \\
\hline & & Các sesquiterpene hydrocarbon & 43,72 \\
\hline & & Các sesquiterpene hydrocarbon chứa oxy & 47,62 \\
\hline & & Hợp chất chưa xác định được & 1,16 \\
\hline & & Tổng số & 94,49 \\
\hline
\end{tabular}

Ghi chú: RI: Chỉ số lưu giữ (Retention indices). 
Tổng số các hợp chất hydrocarbon trong tinh dầu gồm 19 chất, chiếm 44,34\% hàm lượng tinh dầu, trong khi tổng số các hợp chất hydrocarbon chứa oxy gồm 18 chất chiếm 48,99\%. Các hợp chất sesquiterpene được phát hiện chủ yếu trong thành phần tinh dầu cành lá $M$. macclurei chiếm $91,34 \%$ trong tổng số $93,33 \%$ hàm lượng các hợp chất đã xác định được. Trong đó, các hợp chất sesquiterpene hydrocarbon gồm 16 chất, chiếm $43,72 \%$, và các hợp chất sesquiterpene hydrocarbon chứa oxy gồm 15 chất, chiếm 47,62\%. Ngược lại, các hợp chất monoterpene chỉ chiếm lượng rất nhỏ $(1,99 \%)$ trong thành phần tinh dầu. Cụ thể các hợp chất monoterpene hydrocarbon gồm 3 chất, chiếm $0,62 \%$ và các hợp chất monoterpene hydrocarbon chứa oxy gồm 3 chất, chiếm $1,37 \%$ (bảng 1).

Nghiên cứu trước đây cho thấy, $\beta$-elemene (một trong 3 thành phần chính của tinh dầu cành lá M. Macclurei) có tác dụng chống viêm, chống ung thư và có khả năng xuyên qua hàng rào máu não. $\beta$-Elemene cải thiện khuyết tật vận động và giảm tình trạng viêm dây thần kinh thị giác ở chuột bị bệnh viêm não và viêm cột sống tự miễn được thử nghiệm (Zhang et al., 2011).

So sánh kết quả phân tích về thành phần hóa học của tinh dầu $M$. macclurei trong nghiên cứu này với các dữ liệu công bố trước đây cho thấy sự khác biệt đáng chú ý. Huang et al. (2009) đã công bố thành phần của tinh dầu lá $M$. macclurei từ Trung Quốc được chiết xuất bằng phương pháp chưng cất lôi cuốn hơi nước và được phân tích bằng phương pháp GC/MS gồm có 45 hợp chất, trong đó các hợp chất chính chiếm tî lệ lớn trong hàm lượng tinh dầu gồm: Caryophyllene $(18,74 \%), \beta$ elemene $(14,56 \%)$, elemol $(13,14 \%)$, và các hợp chất có hàm lượng tương đối lớn tiếp theo gồm: $\gamma$-Elemene $(9,18 \%), \quad \alpha$-eudesmol $(7,22 \%), \quad \alpha$-caryophyllene $(5,20 \%)$, và $\gamma$ eudesmol $(4,90 \%)$. Nghiên cứu của chúng tôi cho thấy, trong thành phần tinh dầu cành lá $M$. macclurei thu từ Hà Giang có các chất chiếm tỉ lệ hàm lượng tinh dầu tương ứng như sau: (E)- $\beta$-caryophyllene $(1,20 \%)$, cis- $\beta$-elemene $(14,30 \%)$, elemol $(1,31 \%)$, và $\gamma$-eudesmol
$(0,67 \%)$, trong khi không phát hiện thấy sự hiện diện của $\gamma$-elemene, $\alpha$-eudesmol, hay $\alpha$ caryophyllene. Nghiên cứu của $\mathrm{Ma}$ et al. (2011) lại chỉ ra thành phần của tinh dầu lá $M$. macclurei chỉ gồm 27 hợp chất, trong đó các hợp chất chính gồm có: $6,9-$-Octadecadiynoic acid, methyl ester, isolongifolene, nerolidol, $\alpha$-copaen-11-ol, $\alpha$-farnesene, $\beta$-maaliene, isocaryophyllene, $\delta$-cadinol, heptanal, và germacrene B. Trong số 11 chất chính của tinh dầu lá $M$. macclurei được $\mathrm{Ma}$ et al. (2011) công bố, chỉ có chất germacrene B được xác định có hàm lượng rất thấp $(0,25 \%)$ trong nghiên cứu của chúng tôi, không có 10 chất khác Như vậy, thành phần hóa học của tinh dầu $M$. macclurei được nghiên cứu và công bố khác nhau, có thể do môi trường sống và thời gian thu hái mẫu khác nhau.

Thành phần hóa học của tinh dầu cành lá M. macclurei trong nghiên cứu này khác với thành phần hóa học của tinh dầu từ các loài khác trong cùng chi Magnolia. Hầu hết các loài trong chi này được phân tích có hàm lượng các chất monoterpene chiếm phần lớn trong tinh dầu của chúng. Những loài này bao gồm: M. acuminata, M. calophylla, $M$. virginiana (Farag et al., 2015), $M$. hypolampra (Liu et al., 2007), $M$. kwangsiensis (Huang et al., 2010; Zheng et al., 2015; Zheng et al., 2019) và $M$. sieboldii (Sun et al., 2014). Trong khi chỉ có ít loài như M. gloriensis (syn. Talauma gloriensis), có các chất sesquiterpene trội trong thành phần tinh dầu của chúng giống với ở $M$. macclurei (Haber et al., 2008). Còn M. grandiflora và $M$. ovata có thành phần chủ yếu trong tinh dầu của chúng có thể là các chất monoterpene (Apel et al., 2009; Farag et al., 2015) hoặc cũng có thể là các chất sesquiterpene (Wang et al., 2009; Scharf et al., 2016).

\section{Hoạt tính kháng vi sinh vật của tinh dầu Magnolia macclurei}

Hoạt tính kháng vi sinh vật của tinh dầu cành lá $M$. macclurei thu được bằng phương pháp chưng cất lôi cuốn hơi nước được đánh giá bằng phương pháp khuếch tán đĩa thạch trên các chủng vi sinh vật được thử nghiệm. Kết quả thu được sau 18-24 giờ trong điều 
kiện nuôi ủ được trình bày trong bảng 2 và hình 2.

Tinh dầu cành lá $M$. macclurei thể hiện hoạt tính ức chế trung bình và yếu (Mothana \& Lindequist, 2005; Philip et al., 2009) đối với cả 3 chủng vi sinh vật được thử nghiệm với đường kính vùng ức chế từ 4 đến $12 \mathrm{~mm}$. Trong sô 3 chủng vi sinh vật được thử nghiệm, $E$. coli và $C$. albicans có tính chịu đựng với tinh dầu $M$. macclurei cao hơn $S$. aureus. Điều này thể hiện thông qua giá trị đường kính vùng ức chế vi sinh vật, tương ứng $4,0 \pm 2,83 \mathrm{~mm}$ và $5,3 \pm 0,35 \mathrm{~mm}$ so với $12,0 \pm 1,41 \mathrm{~mm}$. Vi khuẩn $S$. aureus (Tụ cầu vàng) được biết là loài gây đau, bỏng, đau họng, nhiê̂m trùng có mủ trên da và các cơ quan nội tạng; $E$. coli có thể gây ra một số bệnh về đường tiêu hóa như viêm dạ dày, viêm đại tràng, viêm ruột, lỵ trực khuẩn; $C$. albicans có thể gây bệnh tưa miệng ở trẻ em và các bệnh phụ khoa.

Hoạt tính kháng vi sinh vật của tinh dầu có thể thay đổi theo mùa. Trong nghiên cứu của mình, Stefanello et al. (2008) đã báo cáo hoạt tính kháng vi sinh vật của tinh dầu từ các thành phần của cây Magnolia ovata (syn. Talauma ovata) thay đổi theo thời gian trong năm. Tinh dầu từ lá thu hái vào tháng mười có hoạt tính mạnh nhất, ức chế 19 trên 22 chủng vi sinh vật được thử nghiệm. Trong khi tinh dầu từ vỏ cây thu hái vào tháng giêng có hoạt tính cao nhất, ức chế được 15 trên 22 chủng vi sinh vật được thử nghiệm. Vì vậy, thời điểm thu hái nguyên liệu để chưng cất tinh dầu nhằm mục đích sử dụng trong $\mathrm{y}$ dược rất quan trọng.

Bảng 2. Anti-yeast and antibacterial activity of essential oils from twigs and leaves of M. macclurei (Mean \pm standard deviation, $\mathrm{n}=2$ )

\begin{tabular}{|c|c|c|}
\hline \multicolumn{3}{|c|}{ Đường kính vùng ức chế (mm) } \\
\hline Staphylococcus aureus & Escherichia coli & Candida albicans \\
\hline $12,0 \pm 1,41$ & $4,0 \pm 2,83$ & $5,3 \pm 0,35$ \\
\hline
\end{tabular}

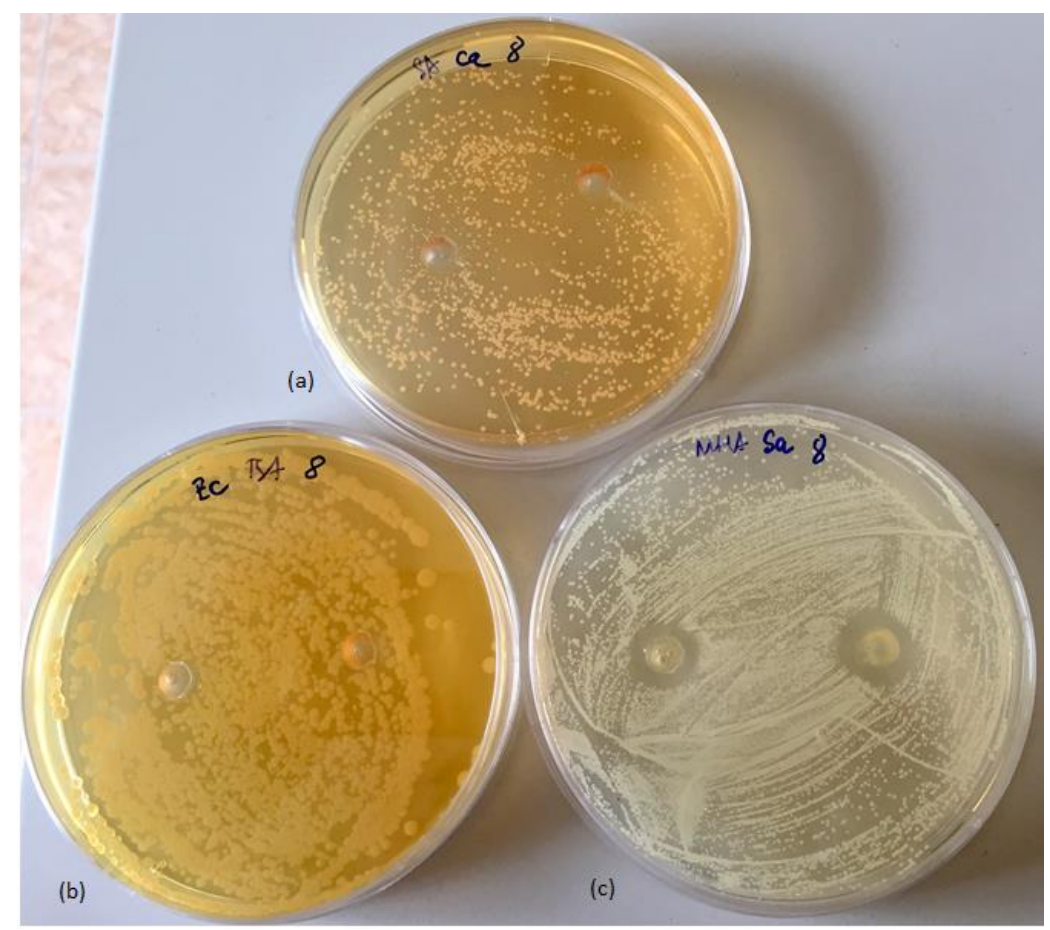

Hìn 2. Antimicrobial activity of essential oil from twigs and leaves of M. macclurei Ghi chú: (a): C. albicans; (b): E. coli; (c): S. aureus 


\section{KẾT LUẬN}

Hàm lượng tinh dầu thu được từ cành lá Giổi búp nhọn $(M$. macclurei) bằng phương pháp chưng cất lôi cuốn hơi nước là $0,254 \%$ (v/w) tính trên khối lượng khô của mẫu. 37 hợp chất đã được xác định trong tổng số 38 chât được phát hiện trong thành phần của tinh dầu, chiếm $93,33 \%$ trong tổng số $94,49 \%$ hàm lượng tinh dầu. Ba hợp chất gồm: cis- $\beta$ Elemene, bicyclogermacrene, và 10-epi- $\gamma^{-}$ eudesmol là các thành phần chính của tinh dầu, chiếm tương ứng $14,30 \%, 18,57 \%$, và 16,86\% Nhìn chung tinh dầu cành lá $M$. macclurei có hoạt tính kháng vi sinh vật kiểm định yếu, với đường kính vùng ức chế ba chủng vi sinh vật: Staphylococcus aureus, Escherichia coli, và Candida albicans từ 4-12 $\mathrm{mm}$.

Lò̀i cảm ơn: Công trình được thực hiện với sự tài trợ kinh phí từ Viện Hàn lâm Khoa học và Công nghệ Việt Nam thông qua Dự án điều tra cơ bản với mã số VAST.ĐTCB.02/17-19 (UQĐTCB.02/17-19). Các tác giả chân thành cảm ơn TS. Nguyễn Tiến Hiệp, Trung tâm Bảo tồn thực vật Việt Nam đã giúp xác định tên thực vật.

\section{TÀI LIỆ THAM KHẢO}

Apel M. A., Lima M. E. L., Moreno P. R. H., Young M. C. M., Cordeiro I., Henriques A. T., 2009. Constituents of leaves essential oil of Talauma ovata A. St.-Hil. (Magnoliaceae). Journal of Essential Oil Research, 21(1): 52-53. https://doi.org/ 10.1080/10412905.2009.9700107.

Balouiri M., Sadiki M., Ibnsouda S. K., 2016. Methods for in vitro evaluating antimicrobial activity: A review. Journal of Pharmaceutical Analysis, 6: 71-79. https://doi.org/10.1016/j.jpha.2015.11.005

Farag M. A., El Din R. S., Fahmy S., 2015. Headspace analysis of volatile compounds coupled to chemometrics in leaves from the Magnoliaceae family. Records of Natural Products, 9(1): 153-158.

Haber W. A., Agius B. R., Stokes S. L., Setzer W. N., 2008. Bioactivity and chemical composition of the leaf essential oil of Talauma gloriensis Pittier (Magnoliaceae) from Monteverde, Costa Rica. Records of Natural Products, 2(1): 1-5.

Huang P. X., Zhou Y. H., Lai J. Y., Li W. G., Liu X. M., 2010. Extraction and analysis of volatile constituents from testa of rare and endangered plant Kmeria septentrionalis. Guihaia, 30(5): 691-695.

Huang R., Tan D., Zheng Y., Huang L., 2009. Chemical Constituents of the Volatile Oils from Leaves of Michelia macclurei Dandy; Journal of Tropical and Subtropical Botany, 17(4): 406-408.

Jorgensen J. H., Ferraro M. J., 2009. Antimicrobial Susceptibility Testing: A Review of General Principles and Contemporary Practices. Clinical Infectious Diseases, 49: 1749-1755. https://doi.org/10.1086/647952.

König, W.A.; Joulain, D.; Hochmuth, D.H.; Terpenoids Library - Terpenoids and Related Constituents of Essential Oils. https://massfinder.com/wiki/Terpenoids_L ibrary. (Truy cập ngày 01/12/2018).

Lee Y. J., Lee Y. M., Lee C. K., Jung J. K., Han S. B., Hong J. T., 2011. Therapeutic applications of compounds in the Magnolia family. Pharmacology \& Therapeutics, 130: 157-176.

Liu J-F, Huang M, Tan, L-Q, Liang J-M, Wu $\mathrm{X}-\mathrm{G} ., 2007$. GC/MS analysis of chemical constituents of volatile oil of Michelia hedyosperma Lew fruits. Chinese Journal of Pharmaceutical Analysis, 27(9): 1481-1483.

Ma H., Sima Y., Hao J., Chen S., Han M., Li D., Xu L., Zhou B., Chai Y., 2011. Study on chemical components in the volatile oils from Michelia polyneura C.Y.Wu ex Law et Y.F.Wu. and Michelia macclurei Dandy. Guangdong Agricultural Sciences, 23: $110-113$.

Mothana R. A. A. and Lindequist U., 2005. Antimicrobial activity of some medicinal plants of the island Soqotra. Journal of Ethnopharmacology, 96: 177-181. https://doi.org/10.1016/j.jep.2004.09.006. 
Philip K., Malek S. N. A., Sani W., Shin S. K., Kumar S., Lai H. S., Serm L. G., and Rahman S. N. S. A., 2009. Antimicrobial Activity of Some Medicinal Plants from Malaysia. American Journal of Applied Sciences, 6(8): 1613-1617. https://doi.org/ 10.3844/ajassp.2009.1613.1617.

Robert P. A., 2001. Identification of essential oil components by gas chromatography/quadrupole mass spectroscopy. Carol Stream, Ill. : Allured Publishing Corporation; 3rd edition. ISBN: 0931710855; 456 pp.

Sarker S. D. and Maruyama Y., 2002. Magnolia. In Medicinal and Aromatic Plants-Industrial Profiles. Vol. 28, Hardman R (Ed). London, UK: Taylor \& Francis, $191 \mathrm{pp}$.

Scharf D. R., Simionatto E. L., Mello-Silva R., Carvalho J. E., Salvador M. J., Stefanello M. É. A., 2016. Cytotoxicity and chemical composition of the essential oils of Magnolia ovata. Latin American Journal of Pharmacy, 35(1): 206-209.

Song X., Lu C., Hu K., Weng X., Jin H., Chen S., 2011. GC-MS analysis of volatile components from barks of Michelia macclurei and their inhibition on in vitro growth of HepG2 cells. Chinese Traditional and Herbal Drugs, 42: 2213-2215.

Stefanello M. É. A., Salvador M. J., Ito I. Y., Wisniewski Jr. A., Simionatto E. L., Mello-Silva de R., 2008. Chemical Composition, Seasonal Variation and Evaluation of Antimicrobial Activity of Essential Oils of Talauma ovata A. St. Hil. (Magnoliaceae). Journal of Essential Oil Research, 20(6): 565-569. https://doi.org/10.1080/10412905.2008.97 00089.

Sun G., Du F., Wan R., 2014. Comparison of biomaterials from essential oils in five parts of Magnolia sieboldii. Applied Mechanics and Materials, 442: 142-146.

$\mathrm{Vu}$ Quang Nam, 2011. Taxonomic Revision of the Family Magnoliaceae from
Vietnam. Dissertation, Graduate University of The Chinese Academy of Sciences, Guangzhou: 241 pp.

$\mathrm{Vu}$ Quang Nam, Hoang Van Sam, Xia NianHe, Phan Minh Sang, 2011. Michelia macclurei Dandy (Magnoliaceae Juss.) A new record species for the flora of Vietnam. Proceedings of the $4^{\text {th }}$ National Scientific Conference on Ecology and Biological Resources: 220-222 (in Vietmamese with English summary).

Wang Y., Mu R., Wang X., Liu S., and Fan Z., 2009. Chemical composition of volatile constituents of Magnolia grandiflora. Chemistry of Natural Compounds, 45(2): 257-258.

Zeng Z., Xie R., Zhang T., Zhang H., Chen J. Y., 2011. Analysis of Volatile Compositions of Magnolia biondii Pamp by Steam Distillation and Headspace Solid Phase Micro-extraction. Jouranl of Oleo Science, 60(12): 591-596.

Zhang R., Tian A., Zhang H., Zhou Z., Yu H., Chen L., 2011. Amelioration of experimental autoimmune encephalomyelitis by $\beta$-elemene treatment is associated with Th17 and Treg cell balance. Journal of Molecular Neuroscience, 44: 31-40. https://doi.org/ 10.1007/s12031-010-9483-1.

Zheng Y. F., Liu X. M., Zhang Q., Lai F, Ma L., 2019. Constituents of the Essential Oil and Fatty Acid from Rare and Endangered Plant Magnolia kwangsiensis Figlar \& Noot. Journal of Essential Oil Bearing Plants, 22(1): 141-150. https://doi.org/ 10.1080/0972060X.2019.1604168.

Zheng Y. F., Ren F., Liu X. M., Lai F., Ma L., 2015. Comparative analysis of essential oil composition from flower and leaf of Magnolia kwangsiensis Figlar \& Noot. Natural Product Research, 30(13): 15526. https://doi.org/10.1080/14786419.2015. 1113410. 